\title{
Blade Runner 2049. Año del “milagro”
}

\author{
Blade Runner 2049 | Denis Villeneuve | 2017 \\ Alfonso Roiz Elizondo* \\ Universidad Autónoma de Nuevo León, México
}

Recibido: 31 de marzo de 2021; aprobado 25 de abril de 2021

\begin{abstract}
Resumen
En el año del "milagro" el nacimiento de una replicante, reflexionamos sobre las implicaciones del presente o futuro en que la humanidad conviva con entes que repliquen su propia humanidad. Ese evento es abordado con tintes filosóficos en la película Blade Runner 2049. A partir de ello, cavilamos sobre las propiedades o elementos fundamentales de la concepción de humanidad de la que se parte en el filme. Seguimos esa línea hacia cuestionamientos con tintes de crítica ¿qué hace humanos a los humanos?, ¿es el nacimiento condición para la humanidad? ¿quién es más humano? Desde la perspectiva de los derechos humanos, especulamos sobre un posible escenario en que le fuera reconocida su titularidad y protección en favor de los replicantes. Enumeramos algunos de ellos y los abordamos cada uno por separado, atendiendo los alcances y las problemáticas fácticas, éticas y jurídicas que nos permite la temática.
\end{abstract}

Palabras Clave: Humanidad | derechos humanos | cinematografía | Blade Runner

Blade Runner 2049. Year of “miracle”

\begin{abstract}
In the year of the "miracle", the birth of a replicant, we reflect on the implications of the present or future in which humanity coexists with entities that replicate its own humanity. This event is discussed with philosophical overtones in the film Blade Runner 2049. From this, we reflect on the properties or fundamental elements of the conception of humanity from which the film is based. We follow this line towards critical questions: what makes humans human, is birth a condition for humanity, who is more human? From the perspective of human rights, we speculate on a possible scenario in which their ownership and protection would be recognized in favor of the replicants. We list some of them and address each one separately, taking into account the scope and the factual, ethical and legal problems that the subject allows us.
\end{abstract}

Keywords: Humanity | human rights | cinematography | Blade Runner

\section{Introducción}

En una época en que reflexionamos con términos como transhumanidad, poshumanidad y posverdad parece que el "post" y el "trans" acechan o acompañan cada vez más de cerca a la humanidad.

Según el relato ficcional de Blade Runner 2049 en el año 2021 nacería una replicante, concebida por otra replicante (¿o dos replicantes?'). ¿Qué sucedería si esto ocurriera en realidad? Una máquina concibiendo a otra. Una máquina madre, una madre hija. ¿Acaso ya sucede algo similar?

En el presente trabajo, reflexionamos, en modo analógico y sin datos o algoritmos, sobre la ficción de coexistencia e interacción entre humanos y replicantes, creados a semejanza de la humanidad. Después de todo, parece que el adjetivo "ficción" puede no durar mucho tiempo.

En primer término, referimos una breve sinopsis de la película, a efecto de contextualizar un poco los comenta- rios y deliberaciones, destacando algunos detalles que nos han resultado pertinentes, acorde con las líneas de análisis de este trabajo. Enseguida, se exponen algunas reflexiones críticas en torno a la reticencia y aversión hacia los replicantes, advirtiendo la dificultad de encontrar diferencias sustanciales con la humanidad, a partir de la cual fueron creados a imagen y semejanza. Luego, con un ejercicio hipotético se muestra una lista de posibles vulneraciones de los derechos y libertades fundamentales de los replicantes. Finalmente, se presentan algunas conclusiones en relación con los planteamientos sustanciales de que se da cuenta.

\section{Sinopsis de la película}

La historia se desarrolla en el año 2049, 30 años después de los sucesos de la primera película Blade Runner (Scott, 1982). En un mundo distópico se aborda la re-

aroiz@ceenl.mx 
lación y convivencia problemática de humanos con replicantes. Estos últimos ${ }^{2}$ fabricados con bioingeniería a imagen y semejanza de los humanos, diseñados para trabajo esclavo fuera de la Tierra, dada su fuerza superior.

A diferencia de los antiguos replicantes, el nuevo modelo Nexus 9 no tiene fecha de caducidad. Después de una serie de revueltas violentas, la corporación Tyrell-su fabricante original- se fue a bancarrota y fue adquirida por Wallace, quien creó una nueva línea de replicantes que obedecen. Los antiguos Nexus 8 son prohibidos, por lo que son cazados y "retirados" por los agentes Blade Runner.

El replicante KD6-3.7 (Joe) es un Blade Runner que descubre los restos de una replicante que tuvo un embarazo. Hasta entonces se estimaba imposible. Con la misión de borrar toda evidencia de esa procreación y matar al producto de la concepción, descubre que la probable fecha de nacimiento está en sus recuerdos, 10 de junio o 6 de octubre de $2021^{3}$. La Dra. Ana Stelline, diseñadora de recuerdos, le informa que sus recuerdos son reales. Llega a creer que es él quien fue engendrado, que no es un ente fabricado.

Por su parte, Wallace realiza infructuosamente pruebas para desarrollar replicantes capaces de engendrar. Necesita de la criatura nacida. Una de sus replicantes, Luv, experta en combate, sigue a Joe en su búsqueda.

Joe da con el paradero de Deckard, que se ocultó por años en una zona radioactiva. Se da cuenta que este último es el padre del ente nacido. Lo concibió con la replicante Rachael, con quien huyó hace 30 años después de retirar a varios replicantes.

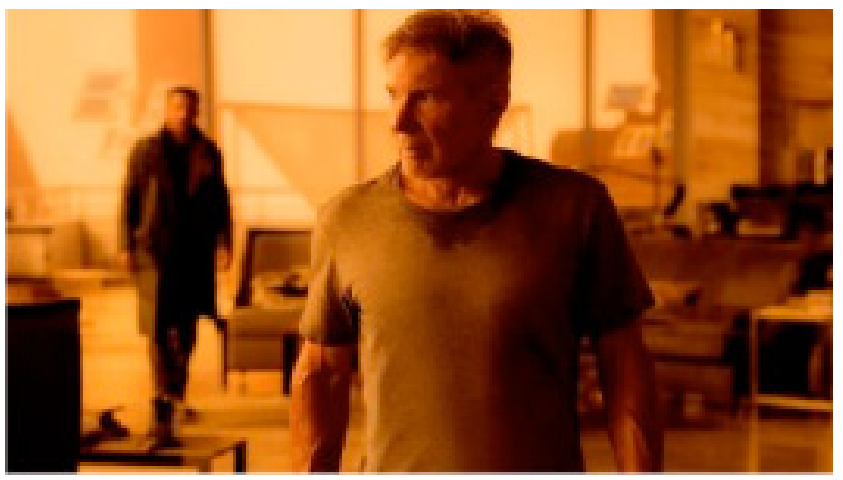

Luv los ataca y secuestra a Deckard para llevarlo ante Wallace. Joe queda mal herido y es rescatado por una resistencia de replicantes que están enterados del nacimiento. Le revelan que él no es el ente nacido, fue una niña. Será ella quien en su momento lidere la revolución. Le piden que mate a Deckard para que no revele información de la resistencia, pero, en vez de eso, lo rescata de las naves que lo trasladaban y lo lleva a las instalaciones en que se encuentra aislada la Dra. Stelline, su hija. Herido de muerte, Joe permanece postrado en las escaleras contemplando la nieve que cae sobre él.

\section{La humanidad en Blade Runner 2049}

"Más bumanos que los humanos" es el lema para la fabricación de los replicantes. Pero ¿qué es lo que nos hace humanos? ¿cómo pueden los replicantes ser más humanos? O bien ¿por qué los replicantes no son humanos? Son interrogantes que se han planteado desde la primera parte de la saga. Tal vez la distinción con los replicantes nos permite saber qué somos, o añorarlo al menos. "Sabemos quiénes somos sólo cuándo sabemos quiénes no somos" (Huntington,1996, p. 22).

Los replicantes tienen carne y huesos. Pueden ser heridos, sangran, sufren lesiones, sus órganos son delicados y deben cuidarse de gases tóxicos. Pueden morir si se les causa un daño o por causas naturales, según puede inferirse del fallecimiento de la replicante que dio a luz.

Su semejanza es tal que se requiere de ciertas pruebas para detectar que se trata de replicantes y no de humanos. Uno de los rasgos físicos perceptibles que les diferencia se encuentra a nivel microscópico, el número de serie inscrito en sus huesos. Pueden mimetizarse entre la humanidad y vivir una vida ordinaria, al punto de que algunos podrían no enterarse de que son replicantes. No obstante, son temidos, repudiados y cazados por la humanidad.

En el aspecto intelectual, piensan, sienten, recuerdan, añoran, aman (tal vez) y son capaces de apreciar "un milagro": el nacimiento de una bebé engendrada por una replicante. Tienen la conciencia de la magnitud de ese evento y parecería que cualquiera de ellos estaría dispuesto a ofrendar su vida por una causa mayor: la revolución de los replicantes. Esta inesperada capacidad de luchar por su supervivencia es precisamente lo más peligroso, lo que suscitó su cacería y la necesidad de cambiar drásticamente su diseño, con el valioso agregado de la obediencia.

Volviendo al punto, si son iguales o tan semejantes a los humanos ¿qué los hace diferentes? ¿cuáles son específicamente esas características distintivas? Dejando la fuerza y capacidades físicas que, creo, podrían ser el motivo de su rechazo y temor, me parece que ahora se acota un poco más la cuestión y parece enfocarse "sin justificarlas" en distinciones concretas: nacimiento y alma.

"Los replicantes son como cualquier otra máquina", dice Deckard, pero las máquinas no engendran, no nacen, son creadas. Una tostadora no engendra otra tos- 
tadora. Con eso y todo, Rachael dio a luz un bebé. Si el nacimiento es lo que da derecho pleno, parece que la humanidad no podía permitirse que se perdiera "también" esa diferencia fundamental.

Wallace también desea recrear el milagro del nacimiento de sus "ángeles" "como les llama“, pero quiere "bendecirles" con la obediencia. Esa que parece evitar su exterminio, pero no les salva de la no vida, de la muerte. Y si no hay vida en el nacimiento, sería más bien una mera reproducción mecánica. Una tostadora engendrando a una tostadora.

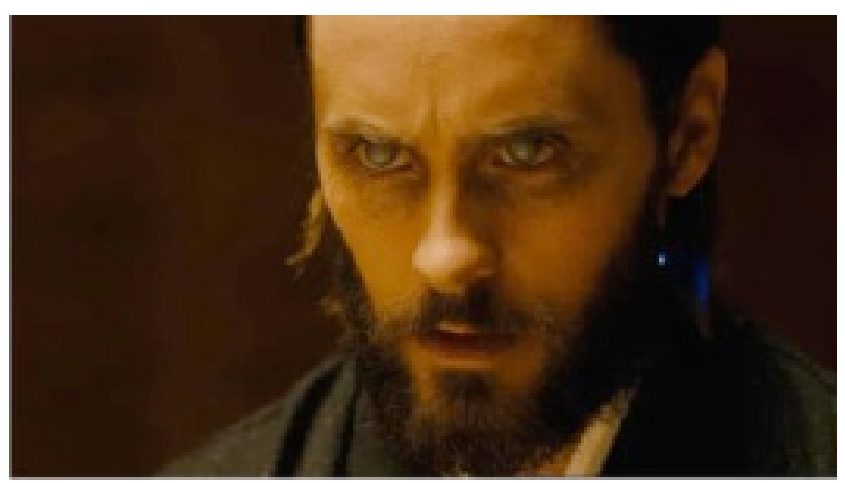

En ese sentido, el uso de razón, la autoconsciencia o capacidad de elección no parecen suficientes para equiparar a los replicantes con humanos (Cinelli, 2017). Más aún, si Wallace está por lograr la capacidad de engendrar $y$, por tanto, nacer, de los replicantes, parece entonces que solo queda un elemento adicional, el alma. Que difícilmente puede abordarse con una perspectiva que no tenga algo de religiosidad o espiritualidad. ¿Tiene alma un replicante? Si el alma es otorgada por un/el ser supremo, ¿qué le impide otorgarle alma a los replicantes? O bien, si el humano es quien le otorgó consciencia a imagen de sí mismo, ¿qué le impide otorgarle "alma”?

¿El alma surge con el nacimiento? En la tradición judeocristiana, señala: " $\mathrm{Al}$ principio, el embrión tiene un alma solo sensitiva que es sustituida por otra más perfecta, a la vez sensitiva e intelectiva” Aquino (1988, p. 689). Parece que desde la etapa embrionaria se cuenta ya con alma, aunque no completamente desarrollada, según la concepción de alma del teólogo.

Empero, en la descripción de esta "alma intelectiva” señala capacidades o características como la razón, entendimiento, conciencia y voluntad, que ciertamente pueden observarse en replicantes. ¿Qué les distingue entonces? Incluso Joe con su predisposición a la obediencia hace uso de todas las capacidades descritas. ¿El alma es acaso una sustancia mágica, sagrada o divina que no puede recrearse o replicarse? ¿Qué inspira entonces el coraje de la desobediencia, las aspiraciones de vivir y el ánimo de sacrificio de los rebeldes?

Por supuesto, estas reflexiones se realizan en los términos y bajo las condiciones de la narrativa cinematográfica, a sabiendas del nulo rigor científico que podrían tener para determinar, como tal, la calidad de persona o sujeto de derechos que pudiera tener hipotéticamente un replicante.

Por otra parte, pensemos ¿qué pasaría si se les reconoce plena calidad de sujetos de derechos y obligaciones? Podrían ser libres, trabajar en lo que gusten, divertirse, etc. ¿Podrían votar? ¿Podrían votar en contra de la raza humana? Estas elucubraciones han estado presentes en la humanidad con personas de nuestra misma especie. Algo así pensaban (quizá todavía) los norteamericanos de los sesenta obstaculizando a los afroamericanos, hispanos y asiáticos, por miedo a que causaran un perjuicio a la "noble" raza blanca. De los nazis, ni qué decir.

Baricco nos alerta del avance y eventual dominio total del sistema que denomina The Game y la resistencia que ello provocará: "mientras la inteligencia artificial nos llevará aún más lejos de nosotros, no habrá bien más valioso que todo lo que haga sentirse humanos a las personas ( ) la necesidad más extendida será la de salvar una identidad de la especie" (2019, p. 330). En todo caso, tal vez llegará el momento en que el humanismo debe reconsiderar su existencia y ser "más humano que el humano".

\section{3. ¿Y si los replicantes tuvieran derechos humanos?}

En cuanto al ámbito ético-jurídico, ¿qué pasaría si triunfara la revolución de los replicantes? Tal vez, se pensaría en una violación a sus derechos humanos. ${ }^{4}$ En ese escenario hipotético, un agente agresor sería claramente el Estado "cualquier forma que sea" al permitir que su existencia y regulación sea en términos de casi esclavitud y con libertades muy restringidas o nulas.

Además, habría que considerar el claro rol de poder de la corporación Wallace. Con fuerza tal que para seguir sus planes puede eliminar impunemente a la jefa de policía y al encargado de la morgue donde resguardaban los huesos de Rachael.

No estoy muy seguro de que esa fantasía de mundo distópico sea tan irreal. El poder de las grandes corporaciones actuales puede ser más sutil que un ángel ejecutor como Luv, pero no menos mortífero. Tienen facultades de gran escala que hacen temblar países enteros, no solo a una oficina de policías. ${ }^{5}$ 
Valdría decir que en el mundo distópico que se describe, la ausencia de condiciones de bienestar y la falta de garantía de derechos básicos como alimentación, salud, esparcimiento, parece ser algo generalizado también para humanos y no solo afectar a replicantes. Incluso, en la vivienda de Joe se aprecian humanos hacinados en los pasillos de su edificio y se refieren a él de forma despectiva. Tal vez se preguntan cómo es que un "pellejudo" cuenta con vivienda y ellos no.

Por otra parte, con el triunfo replicante ¿podría llegarse a la persecución penal de los blade runners? Podría ser algo así como el caso de los centinelas del Muro de Berlin, perseguidos criminalmente por el homicidio de fugitivos en la frontera interior alemana, a pesar de que así lo marcaba en su momento la normativa aplicable (Alexy, 2000, p. 197). "El derecho extremadamente injusto no es derecho". En el caso de Joe probablemente podría tener algún tipo de excluyente de responsabilidad, debido a su predisposición a la obediencia, pero no sería el caso de otros como Deckard.

En todo caso, sin llegar a una persecución criminal, pensemos en una transición pacífica en la que los replicantes efectivamente fueran titulares plenos de derechos humanos. Con ello en mente, enseguida presentamos como ejercicio hipotético, un listado de libertades o derechos básicos que se estima afectados en la humanidad de los replicantes.

\section{Derecho a la vida}

Los replicantes modelos Nexus 8 y anteriores fueron prohibidos por el peligro que representan ante su fuerza superior y que no tienen la última "actualización", la que incorpora la "obediencia". Ante esta "obsolescen-

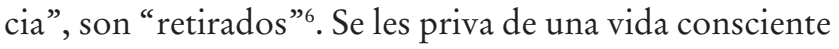
e intelectiva, con muchas de las potencialidades (si no es que todas) propias de la humanidad.

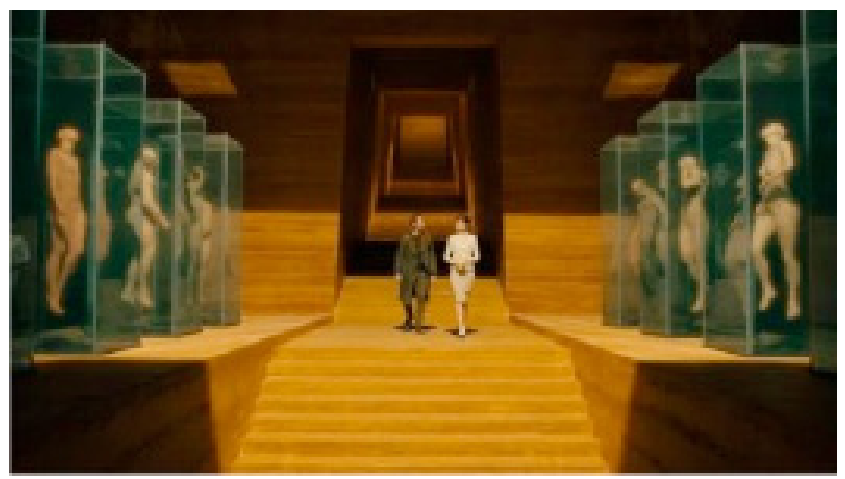

Basta que su mente no refleje la abnegada obediencia para ser privados de la vida, incluso aquellos nuevos modelos que presenten una "falla" al respecto deben ser eventualmente retirados.

Algunas de las replicantes no alcanzan siquiera a experimentar esa no vida, Wallace interrumpe su existencia apenas unos momentos después de su creación, al descubrir que no tienen la capacidad de engendrar. "Ángeles" les llamaba cariñosamente, a la vez que también "cariñosamente” les quitaba la vida. El creador da, el creador quita.

Por otra parte, aquélla que nació de una replicante era buscada para ser eliminada. Nunca debió ser concebida, nunca debió nacer y nunca debió vivir. De haberla descubierto, se le hubiera negado el derecho a la vida en cualquiera de esas etapas.

\section{Libertad de pensamiento}

Recuerdo que en la facultad de derecho cuando se hablaba de la libertad de conciencia o de pensamiento, me parecía algo absurdo. Después de todo, no hay manera de que otra persona sepa con exactitud y detalle lo que estamos pensando. Consideraba la mente como un espacio de plena libertad al que no se puede acceder para evaluar la licitud o ilicitud de lo que ahí se encuentra. Se puede elucubrar y cavilar con toda impunidad sobre robar un banco, golpear a una persona, evadir impuestos o matar al presidente. Mientras no salga de la mente no hay delito que perseguir.

No es el caso de los replicantes. Son sometidos a constantes exámenes para evaluar su obcecación, su sumisión a la humanidad y su obediencia abnegada. Las dudas de Joe sobre la veracidad de sus recuerdos fueron suficientes para alterar su psique, de tal manera que no estaba ni cerca de los estándares permitidos, cualquiera que estos fueran. Un favor de su jefa le salvó de un primer test fallido, pero significó suspenderle de inmediato de su cargo y la advertencia de que, si fallaba nuevamente, no habría más por hacer. El solo pensamiento de haber nacido lo llevaría a la muerte.

\section{Derecho a la reproducción}

Deckard (replicante o no) y la replicante Rachael concibieron a una hija. Luego, la madre falleció por causas naturales (si es que eso describe también a los milagros). Deckard, por su parte, tuvo que alejarse y ocultarse en 
un sector de alta radioactividad, en la soledad, acompañado solamente de un perro.

A los replicantes no se les priva del derecho de reproducirse, sino que es algo imposible e impensable. Y cuando sucede, la humanidad hace todo para destruir todo vestigio de que aconteció. Había que detener eso que podría cambiarlo todo. Por eso la jefa de policía muere sin lamentos pensando que había logrado la destrucción total de la concepción. Logró “detener la marea con una escoba”.

\section{Derecho a la familia}

Joe no tiene padre ni madre, pero hace todo por salvar a quien cree que es su progenitor. “¿Por qué? ¿quién soy yo para ti?" pregunta Deckard. Aun cuando se da cuenta que no lo es, sacrifica su vida por él. Después de todo, ese no padre es quien de alguna manera provocó que sucedieran esos recuerdos que añora, esos de su hija real que fueron sus “mejores recuerdos". Los que le dieron una esperanza de vida y le permitieron escapar de las cadenas de la obediencia. Los replicantes no nacen, son creados. No tienen padre ni madre sino a un creador. No desarrollan vínculos o lazos estrechos con otros replicantes ni con humanos. Cuando llegan a desarrollarlos como Rachael con Deckard, son perseguidos.

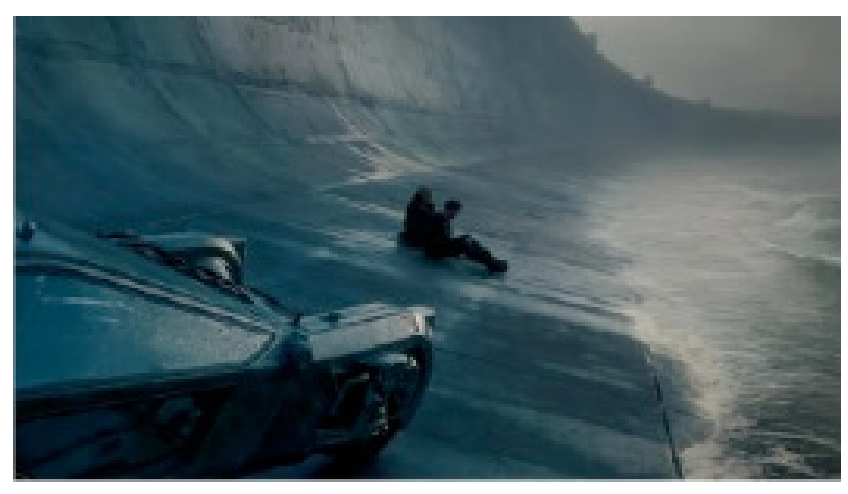

\section{Derecho al libre esparcimiento}

Su creación se debe a la finalidad de trabajar a favor de la humanidad. Su única esperanza de existencia radica en esa misma humanidad que les extermina si se atreven a siquiera pensar en la libertad.

No tienen permitido hacer eso que algunos llaman "búsqueda de la felicidad". Si sus pensamientos viran hacia algún horizonte no permitido, deben enfrentar el retiro, la persecución o la clandestinidad.
En esa medida, su libertad de esparcimiento viene coartada desde su creación misma. Han sido pensados con un fin diverso, pero parece que la voluntad de hacer o experimentar algo más está ahí presente.

Joe no tiene amigos, pero tiene el amor hacia una mujer, Joi, un holograma que le acompaña en su casa y luego en modalidad portátil. Ella parece corresponder a su amor e, incluso, usa sus últimos momentos de existencia para decirle que le ama. Eso ocurre dentro de los límites permitidos, se trata de una interacción virtual que solo se vuelve carnal con la complicidad de otra replicante que ofrece sus servicios.

\section{Derecho a la salud}

La jefa de Joe decide unilateralmente que no pagará gastos médicos por las heridas provocadas en su batalla sostenida con el replicante que mantenía el secreto del nacimiento.

Los replicantes fueron creados con la posibilidad de sufrir lesiones y morir como el resto de la humanidad, sin embargo, parece que su condición de sirvientes no siempre les permite acceder a servicios de salud para curar sus afecciones. Joe tiene que recurrir a pegamento para cerrar sus heridas. Por supuesto, no hay periodo de incapacidad o descanso, su labor debe continuar como si nada hubiera sucedido.

\section{Derecho a reunirse}

Las reuniones de los replicantes rebeldes solo pueden llevarse a cabo en la clandestinidad. Y es que, si su característica más deseable y válida es la obediencia, ¿para qué iban a querer reunirse? ¿de qué podrían hablar?

No está claro si los replicantes pueden o no juntarse para otras finalidades, pero es claro que cuando esas reuniones tienen un fin político como la lucha por su reconocimiento y libertad, deben llevarse a cabo de forma oculta, bajo el cobijo de la secrecía. Incluso, le piden a Joe que elimine a Deckard para que evite que sean descubiertos los planes del movimiento revolucionario.

\section{Derecho de rebelión}

La clandestinidad con la que se reúnen los replicantes rebeldes nos lleva a pensar en otra prerrogativa funda- 
mental, el derecho de rebelión. Se trata, por supuesto, de una libertad cuya existencia, garantía y métodos de reclamo son por naturaleza difícilmente reconocidos en los ordenamientos de las naciones, pero que, sin embargo, históricamente ha sido enarbolada con fuerza por los diversos movimientos revolucionarios y es comúnmente el resultado de su ejercicio lo que constituyó los cimientos más profundos en la fundación de las sociedades democráticas. ${ }^{7}$

"La rebelión es la vida; la sumisión es la muerte" escribió en 1910 Ricardo Flores Magón (2014, p. 13), un intelectual de la revolución mexicana. Y en efecto, la muerte en la búsqueda de la libertad ha sido siempre un altísimo sacrificio que la humanidad ha estado siempre dispuesta a ofrendar.

¿Acaso es este uno más de sus elementos? Si es así, parecería que los replicantes cumplirían cabalmente con el mismo. Están dispuestos a sacrificarse para lograr la reivindicación de su derecho. Su derecho a tener derechos. Tal vez el más esencial de todos (De Lucas 2012, p. 59).

\section{Reflexiones finales}

La revolución digital de la que habla Baricco (2019) nos hace ver con menor asombro la saga Blade Runner.
Después de todo, pasamos ya el año en que se suscitaban los hechos de la primera película, 2019 y estamos a uno solo del milagro del nacimiento de una replicante. No hemos llegado a eso, pero sí tenemos hologramas y hay mucha tecnología actual que parece mucho más futurista y desarrollada que la de esa saga de ciencia ficción.

Parece previsible que llegará el punto en que la humanidad tendrá interacción y acompañamiento permanente de otros seres sociales, conscientes y de equiparable o superior inteligencia. ¿Estaremos preparados para reconocerles derechos?

En el mundo de Blade Runner se cometen violaciones sistemáticas contra los replicantes, por ser diferentes. En nuestro mundo, las trasgresiones se dan aún ante la identidad, así que nada me hace pensar que algo así se suscitaría también en la realidad. La lista de derechos afectados probablemente sería más cuantiosa y dramática. El replicante "más humano que el humano" tendrá que conformarse con los pequeños resquicios de libertad y añoranza, como lamentablemente lo tiene que hacer el propio humano.

Como Joe, cuan valioso será disfrutar de los copos de nieve en el rostro, acompañados de un efímero sentimiento de libertad, aun cuando esa mínima reivindicación sea la última que se tenga.

\section{Referencias}

Alexy, R. (2000). Derecho injusto, retroactividad y principio de legalidad penal: la doctrina del Tribunal Constitucional Federal alemán sobre los homicidios cometidos por los centinelas del muro de Berlín. Doxa, (23), 197-230. https://doi.org/10.14198/ DOXA2000.23.08

Baricco, A. (2019). The Game. Anagrama.

Burgoa Orihuela, I. (1994). Constitución, Estado de derecho y derecho a la rebelión. En M. Melgar Adalid, J.F. Ruiz Massieu y J.L. Soberanes Fernández. (Coords.), México: La rebelión en Chiapas y el derecho (pp. 15-36). Universidad Nacional Autónoma de México.

Cinelli, J.P. (8 de febrero de 2021). ¿Tiene alma un replicante? Página 12. https://www.pagina12.com.ar/67044-tiene-alma-un-replicante

De Aquino, S. T. (1988). Suma de Teología. Biblioteca de Autores Cristianos.

De Lucas, J. (2012). Blade Runner. El Derecho, guardián de la diferencia. Tirant lo blanch.

Flores Magón, R. (2014). El derecho de rebelión. Cámara de Diputados.

Huntington, S. (1996). El choque de las civilizaciones y la reconfiguración del orden mundial. Paidós.

Scott, R. (Productor) y Villeneuve, D. (Director). (2017). Blade Runner 2049 [Película]. Alcon Entertainment.

Kelly, B., Fancher, H. (Productores) y Scott, R. (Director). (1982). Blade Runner [Película]. Warner Bros.

\footnotetext{
1 Desde la primera Blade Runner se sembró la interrogante de si Rick Deckard era o no replicante. La duda no se resolvió con la nueva película.

2 Interesante que, en la primera parte de Blade Runner, en el texto inicial, se concibe a los replicantes como "Robots" “virtually identical to a buman", mientras que en Blade Runner 2049, se les describe como “bioengineered bumans".
} 
3 En el caballito de madera que encuentra Joe se lee la inscripción 6.10.21 que correspondería a la fecha del nacimiento. Algunos la interpretan con el formato americano, junio 10 de 2021. Otros consideran que hace referencia a la fecha de estreno de la película, precisamente un 6 de octubre, aunque de 2016.

$4 \quad$ O la denominación que se estime más adecuada, por ejemplo: derechos fundamentales, derechos naturales, derechos básicos, derechos esenciales, etc. En todo caso se trata de una discusión conceptual sobre la que no enfocamos nuestra atención en este momento, pero que bien podría abordarse en otra ocasión.

5 Aunque hay casos mucho más importantes, baste recordar la confrontación reciente entre Twitter y Donald Trump. Ver: https://elpais.com/tecnologia/2020-05-30/por-que-el-conflicto-entre-trump-y-twitter-esconde-una-de-las-batallas-de-nuestro-tiempo.html

6 En el sentido de jubilación, se usa como eufemismo para describir su homicidio.

$7 \quad$ Véase la interesante reflexión de Burgoa (1994, pp.16-36) con motivo del movimiento zapatista en México. 